\title{
FORMAÇÃO CONTINUADA EM EDUCAÇÃO DAS RELAÇÕES ÉTNICO- RACIAIS: O(A) PROFESSOR(A) TUTOR(A) NA CONSTRUÇÃO DO CONHECIMENTO
}

\author{
FORMACIÓN CONTINUA EN EDUCACIÓN DE LAS RELACIONES ÉTNICO- \\ RACIALES: EL(LA) PROFESOR(A) TUTOR(A) EN LA CONSTRUCCIÓN DEL \\ CONOCIMIENTO
}

\author{
CONTINUING EDUCATION TRAINING OF RACIAL-ETHNIC \\ RELATIONS: (A) TEACHER TUTOR(A) IN THE CONSTRUCTION OF \\ KNOWLEDGE
}

\author{
Paulino de Jesus Francisco CARDOSO ${ }^{1}$ \\ Simone Barboza de CARVALHO ${ }^{2}$ \\ Karla Leandro RASCKE ${ }^{3}$ \\ Carina Santiago dos SANTOS ${ }^{4}$ \\ Cristiane Mare da SILVA ${ }^{5}$
}

Resumo: Este artigo tem por objetivo apresentar experiências de tutoria ocorridas em 2013 e 2014 por meio de cursos de formação continuada de professores(as) oferecidos pelo Núcleo de Estudos Afro-Brasileiros da Universidade do Estado de Santa Catarina (NEAB-UDESC) em consonância com a Lei Federal 10.639/03. Procuramos discutir as possibilidades promovidas pelos ambientes virtuais de aprendizagem para o desenvolvimento de formações destinadas a professores e professoras preocupados com a qualidade e o efetivo diálogo na construção de uma sociedade que valorize as diferentes origens de suas cidadãs e seus cidadãos, sem hierarquizá-las. Analisamos o papel do(a) professor(a) tutor(a) na construção do conhecimento em cursos de formação continuada direcionados a professores(as) da educação básica.

PALAVRAS-CHAVE: Formação continuada. Construção do conhecimento. Professor tutor.

RESUMEN: Este artículo tiene el objetivo de presentar experiencias de tutoría ocurridas en 2013 y 2014 por medio de cursos de formación continua de profesores(as) ofrecidos por el Núcleo de Estudios Afro-Brasileños de la Universidad del Estado de Santa Catarina (NEAB-UDESC) en conformidad con la Ley Federal 10.639/03. Buscamos discutir las posibilidades impulsadas por los ambientes virtuales de aprendizaje para el desarrollo de formaciones destinadas a profesoras y profesores preocupados con la cualidad y el efectivo diálogo en la construcción de una sociedad que valore los diferentes orígenes de sus ciudadanas y ciudadanos, sin jerarquizarlos.

${ }^{1}$ Professor titular da Universidade do Estado de Santa Catarina. Coordenador do NEAB-UDESC e Presidente da ABPN. E-mail: paulino.cardoso@gmail.com

${ }^{2}$ Mestra em Educação pelo PPGE-UDESC. Graduada em pedagogia pela USP. Pesquisadora associada ao NEAB-UDESC. E-mail: sicarvalho84@gmail.com

${ }^{3}$ Doutoranda em História Social pela PUC-SP e mestra em História Social também pela PUC-SP. Professora tutora na EaD do CEAD-UDESC, curso de Pedagogia. Pesquisadora associada ao NEABUDESC e ao CECAFRO-PUC/SP.

${ }^{4}$ Mestra em História pelo ProfHistória UDESC. Coordenadora do Núcleo EJA Centro I- Matutino da Rede Municipal de Ensino de Florianópolis. Pesquisadora associada ao NEAB-UDESC.

${ }^{5}$ Mestra em História Social pela PUC-SP. Secretária da UNEGRO-SC. Pesquisadora associada ao NEABUDESC. 
Analizamos el papel del (de la) profesor(a) tutor(a) en la construcción del conocimiento en cursos de formación continua direccionados a profesores(as) de la educación básica.

PALABRAS CLAVE: Formación Continua. Construcción del Conocimiento. Profesor Tutor.

ABSTRACT: This article objective to present tutoring experiences that occurred in 2013 and 2014 through continuing education courses for teachers offered by the AfroBrazilian Studies Center of the State University of Santa Catarina (NEAB - UDESC) in line with the Federal Law 10.639/03. We seek to discuss the possibilities offered by virtual learning environments for the development of training for teachers concerned with the quality and effective dialogue in building a society that values the diverse backgrounds of its citizens, without rank them. We analyze the role of teacher the construction of knowledge on continuing education courses aimed at teachers of basic education.

KEYWORDS: Education of ethnic-racial Relations. Teacher training. Distance education.

\section{Introdução}

O presente artigo é resultado das experiências de tutoria nos cursos de extensão a distância (EaD) promovidos pelo Núcleo de Estudos Afro-Brasileiros da Universidade do Estado de Santa Catarina (NEAB-UDESC). Buscamos refletir a respeito dos componentes estruturantes da educação a distância, bem como sobre o papel da tutoria. Além disso, o manuscrito procura ressaltar a importância de uma formação que agregue aspectos inerentes a uma sociedade igualitária, como a educação para as relações étnicoraciais (ERER), praticamente inexistente na formação inicial da maioria dos(as) professores(as). Temos como foco os cursos de extensão centrados na Lei Federal $\mathrm{n}^{\mathbf{o}}$ $10.639 / 2013$ e seus desdobramentos.

A educação a distância tem expandido seus horizontes nas duas últimas décadas, principalmente quanto às possibilidades de acesso ao ensino superior e também aos cursos de formação continuada, após a etapa inicial de formação (graduação). Esta última situação interessa particularmente neste trabalho devido às nossas múltiplas experiências de formação de professores(as) da educação básica, em especial quanto ao tema das relações étnico-raciais e história e cultura afro-brasileira e africana, conforme a Lei Federal 10.639/03 e as Diretrizes Curriculares Nacionais para a Educação das Relações Étnico-Raciais e História e Cultura Afro-Brasileira e Africana (2004) 
dispostas pelo MEC para orientação sobre a implementação da referida lei em todos os níveis de ensino.

\section{A EAD e suas possibilidades para a formação de professores (as)}

O alcance do ensino a distância é um dos fatores que corroboram para seu fomento, pois possibilita ao aluno assistir às aulas em sua própria cidade, sem a necessidade de deslocamento diário até a Instituição de Ensino Superior (IES) ou até mesmo a mudança de município ou estado. Configura inúmeras possibilidades a partir de diferentes ferramentas, proporcionando acesso ao conhecimento por meio de tecnologia que atinge múltiplos lugares concomitantemente. As tecnologias da informação e da comunicação, como bem apontam Coelho e Ivashita (2009, p. 7551-2), expandiram as possibilidades educacionais, oportunizando formação especializada a diferentes sujeitos em lugares diversos, sem necessidade de presença física aglomerada em único espaço (local).

Estas novas tecnologias, em termos educacionais, demandam pensarmos métodos e possibilidades didáticas, relações de aprender e produzir conhecimento, para além das formas tradicionais pautadas no ensino presencial. Neste sentido, consideramos que a educação a distância "não oferece um ensino centrado no professor e sim pautado na capacidade do aluno em superar-se e buscar/construir seu próprio conhecimento, trata[ndo]-se de um ensino centrado no aluno e em suas necessidades" (IVASHITA; COELHO, 2009, p. 7552).

Dentre os inúmeros ambientes virtuais de aprendizagem (AVA), para este trabalho desenvolvido pelo NEAB-UDESC na formação continuada de professores (as), utilizamos a Plataforma Moodle (Modular Object-Oriented Dynamic Learning Environment), que permite a gestão de cursos a distância, por meio de um software livre desenhado para auxiliar educadores (as) a criar cursos on-line com ferramentas e layouts personalizados às demandas e interesses de cada instituição, centro de ensino ou curso.

Aliados às ferramentas que plataformas virtuais possibilitam para o trabalho qualificado da educação a distância, diferentes atores são fundamentais no processo de ensino-aprendizagem da $\mathrm{EaD}$, atuando em diversas funções existentes nesta modalidade de ensino, quais sejam: coordenação de tutoria, professor (a) conteudista, professor (a) formador (a), professor (a) tutor (a), web designer, designer instrucional e suporte 
técnico. Estes (as) profissionais são fundamentais na construção crítica do conhecimento em ambientes virtuais de aprendizagem. Devido aos objetivos do presente texto, focamos nossos olhares no papel do (a) professor (a) tutor (a) no processo pedagógico em cada sala virtual em que atua.

Nosso trabalho volta-se especificamente para cursos de formação continuada para professores (as) da educação básica, com temáticas voltadas aos estudos de Áfricas e diásporas, bem como relações raciais no Brasil, possibilitando a diferentes educadores e educadoras uma formação de qualidade nestes temas. Neste sentido, pautamos nossas formações em materiais didáticos e abordagens específicas que atendam às legislações vigentes, oportunizando formação a estes diferentes profissionais que não tiveram acesso a estes estudos em seu curso inicial na educação superior, em distintas áreas do conhecimento que envolvem as licenciaturas. Como bem apontam Moreira e Almeida (2014, p. 406), não "podemos nos ancorar apenas na perspectiva da formação, necessitando buscar, por meio da formação continuada, ou da pesquisa da própria prática, preencher as lacunas que ficaram e as 'ausências' da formação inicial" (ensino superior).

Percebemos que estas formações constituem uma possibilidade para pensar “criticamente sobre a nova prática preconizada pelas reformas educacionais, sobre o que está sendo solicitado deles, sobre as alterações que precisam fazer em sua prática atual, para que consigam aprender a atuar de uma maneira nova (NUTTI; REALI, 2002, p. 40 apud BORGES; REALI, 2012, p. 3). Assim, cremos que a formação necessita apresentar conexão direta "com a realidade da educação, desenvolvendo meios para a superação das dificuldades e dos problemas da prática docente" (BORGES; REALI, 2012, p. 4).

\section{A Formação Continuada e a Lei Federal 10.639/03}

A formação continuada a partir da Lei Federal 10.639/03 oportuniza debatermos com professores (as) e demais educadores (as) das redes de ensino sobre o papel e a responsabilidade de todos (as) nós no que diz respeito ao enfrentamento das desigualdades raciais na escola e fora de seus muros, em diálogo com demais funcionários (as) do corpo escolar, já que contamos com outros (as) educadores (as) ademais dos (as) professores (as). Igualmente, necessitamos discutir a manutenção de 
privilégios em uma sociedade historicamente racista como a nossa, ao deflagrar o lugar do branco nas relações raciais.

Vivemos um momento de grande responsabilidade social e com o peso de rever toda a manutenção das hierarquias raciais estruturantes nas relações pessoais e institucionais no país, e para tanto, a educação se constitui como peça chave neste processo, e tampouco pode ser trabalhada de forma isolada, já que o racismo não se trata apenas do não conhecimento ou falta de esclarecimento, mas da manutenção de privilégios e do poder de brancos sobre não brancos.

A Lei 10.639/03 tem como principal objetivo que as diretrizes do currículo nacional se façam presentes em planos de aulas e ações pedagógicas e, principalmente, na abordagem dos conteúdos, ressignificando e incorporando este espaço escolar, como lugar em que todos os brasileiros e as brasileiras devam sentir-se representados e acolhidos. Sobre o papel da escola, Cardoso e Rascke destacam a

[...] importância da construção de uma educação transformadora, pautada na reeducação das relações, dos conceitos e das práticas. A Lei Federal 10.639/03 legitima a luta por direitos e por uma história não eurocêntrica, que sempre esteve pautada na figura de grandes heróis brancos (CARDOSO; RASCKE, 2014, p. 23).

Das inúmeras ações governamentais desenvolvidas na última década, destacamse aquelas voltadas para o enfrentamento das desigualdades raciais na Educação. Deste modo, os NEABS, por meio da Comissão Técnica Nacional para Assuntos Relacionados à Educação dos Afro-Brasileiros do Ministério da Educação (CADARA), do Conselho Nacional de Educação (CNE), e apoio aos Fóruns Estaduais de Educação das Relações Étnico-Raciais (FEDERER), têm amparado iniciativas importantes tanto no que diz respeito à criação de instrumentos normativos, como na produção de materiais didáticos para atividades pedagógicas, em especial, as ações de formação continuada de professores(as), posto a necessidade vigente em propor uma formação da qual professores(as), em sua maioria, não tiveram acesso durante todo o seu percurso na universidade.

Neste sentido, a criação da Secretaria de Educação Continuada, Alfabetização, Diversidade e Inclusão (SECADI-MEC), possui como um de seus propósitos contribuir para a implementação da Lei Federal 10.639/03, sendo que o PPDEE-UNIAFRO, um dos editais em que fomos contemplados, é fruto de ações vinculadas a esta secretaria. $\mathrm{O}$ UNIAFRO, assim como o PROEXT-SESu, foi responsável, ao longo da última década, 
pelo oferecimento de milhares de vagas em cursos presenciais, semipresenciais e a distância, buscando suprir a demanda de docentes em termos de ferramentas para a construção da Educação das Relações Étnico-Raciais (ERER), permitindo novas práticas e contemplando a História e Cultura Africana e Afro-Brasileira nas escolas da educação básica, nas formações de educadores (as) sociais que atuam em diferentes projetos e constituição das militâncias negras em diversos espaços, municípios e estados.

Outro fator importante no desenvolvimento dos cursos de formação foi contar com a presença de militantes históricos(as) da luta antirracista do estado de Santa Catarina e do Brasil que acompanharam, desenvolveram e agora implementam a Lei Federal 10.639/03, como o professor Paulino de Jesus Francisco Cardoso, coordenador do projeto e conteudista na elaboração do material didático do curso, a professora Jeruse Maria Romão, formadora, oficineira e conteudista, o professor Walmir Brito, educador, conhecido como mestre Jimmy Wall na capoeira, e a professora Estela Cardoso, tutora e oficineira. Toda a equipe de profissionais e cursistas compartilharam experiências e aprendizados com estes (as) militantes, intelectuais e educadores(as). Vidas em que a esperança de um Brasil com equidade racial e social se fazem possíveis, pois conhecer suas histórias nos inspira, apontando que suas vidas, não raras vezes, se mesclam na participação e construção de um Brasil plural e não racialista.

É neste contexto nacional que se inscreve nossa experiência como membros da equipe de formação de professores (as) no NEAB-UDESC, uma equipe ampla de formadores(as), tutores(as), coordenadoras de tutoria, conteudistas, coordenação geral e bolsistas, com o objetivo de pensar, refletir e estimular a formação continuada e a diversidade cultural, especialmente na educação básica.

\section{Propostas de formação continuada em consonância com a Lei Federal 10.639/03}

O primeiro passo para a formação de professores (as), de acordo com a legislação vigente, está no reconhecimento das tensões do espaço escolar como importante ponto de partida para transformação social, percebendo suas peculiaridades, pontuando práticas docentes que precisam ser revistas, buscando caminhos de modo coletivo e assumindo a pauta da valorização da diversidade étnico-racial como bandeira de todos(as) os(as) educadores(as), independentemente de suas origens. 
Outro ponto fundamental para que as propostas de cursos de formação se adequem à legislação está no discernimento dos (as) formadores (as) no que diz respeito ao conteúdo abordado durante o curso. É preciso trabalhar para o fim de estereótipos sobre as Áfricas e o Brasil afro-brasileiro, criticando uma essência cultural que cristaliza os sujeitos e suas vivências. Mortari (2015) corrobora com este encaminhamento quando defende que

[...] a história dos africanos e dos afrodescendentes no Brasil não se resume a escravidão e essa afirmação implica em pensar esses sujeitos em sua humanidade e alteridade. É preciso aprender a estudar, reconhecer e visibilizar essas outras histórias para além da figura de objetos e ver essas populações como sujeitos históricos diaspóricos, como pessoas (p. 145).

Contando com o engajamento de professores (as) conscientes de seus papéis como agentes colaboradores efetivos na construção de uma educação plural e inclusiva, para além do campo do habitual e fugindo dos olhares eurocêntricos, as experiências de cursos de formação podem ser proveitosas e auxiliar na transformação das práticas docentes na educação básica e também superior, através do diálogo e trocas de experiências.

\section{O NEAB-UDESC e seu papel político e educacional}

O NEAB-UDESC surgiu de forma institucionalizada a partir do ano de 2003, figurando como um espaço em que a temática da educação das relações étnico-raciais possui protagonismo nas atividades de pesquisa, ensino e extensão da universidade a qual pertence. Os projetos desenvolvidos articulam produção, transmissão e apropriação de campos do conhecimento, especialmente das ciências sociais, humanas e políticas, que pautem os temas em torno da diversidade, sobretudo, a diversidade étnico-racial.

As ações desenvolvidas nos projetos do núcleo estão voltadas à garantia dos direitos fundamentais e à valorização da dignidade humana - condições essenciais para o enfrentamento das desigualdades e para a promoção da mobilidade/ascensão social. De acordo com o Regimento Interno ${ }^{6}$, dentre seus inúmeros objetivos, está o de “colaborar para a implementação das Leis Federais n”. 10.639/03 e 11.645/08, dos pareceres CNE/CP 003/04 que definem as diretrizes Curriculares Nacionais para

${ }^{6}$ Regimento Interno do Núcleo de Estudos Afro-Brasileiros da UDESC, aprovado em 2012. 
Educação das Relações Étnico-raciais e o Ensino de História Afro-Brasileira e Africana" (capítulo 2, art. $4^{\circ}$ ). Dessa forma, o NEAB-UDESC vem, regularmente, promovendo parcerias com instituições universitárias, entidades do Movimento Negro catarinense e organizações antirracistas, a fim de contribuir para a mudança da cultura institucional de nossas universidades e de outras organizações públicas, em especial.

$\mathrm{Na}$ busca pela expansão das discussões às regiões que necessitam de formação na temática, desde 2005, em parceria com o Centro de Ensino a Distância da UDESC, são oferecidos alguns cursos na modalidade $\mathrm{EaD}$, entendendo que esta permite, entre outros objetivos, propiciar uma democratização do ensino. Vemos a seguir como alguns destes cursos foram sistematizados.

\section{Estrutura dos cursos de formação continuada do NEAB-UDESC}

O NEAB-UDESC tem atuado desde sua criação, em 2003, com diferentes projetos de pesquisa, ensino e extensão, de modo a construir narrativas, práticas e metodologias capazes de atender diferentes demandas no âmbito da Lei Federal 10.639/03, organizando "textos acadêmicos, cursos de extensão, disciplinas de graduação, palestras e debates, entre outras ações, com foco na Educação das relações Étnico-Raciais" (GOMES, 2015, p. 93).

Diante das inúmeras demandas que envolvem a formação inicial e continuada de professores(as), bem como a necessidade de pesquisas que atentem para os temas africanos e da diáspora, o NEAB-UDESC volta sua atenção a estas necessidades, preparando material didático específico e permitindo que professores(as) recebam formação adequada às demandas e realidades escolares onde atuam, visto que nem sempre a formação inicial (oferecida na graduação) aborda em suas grades tais assuntos, perspectivas e questionamentos.

Os cursos de formação ofertados pelo NEAB-UDESC possuem uma preocupação com a prática pedagógica permanente, no sentido de uma ação que seja desenvolvida quotidianamente no espaço escolar, muito além de algumas ações pontuais voltadas apenas para a Semana da Consciência Negra. Neste sentido, assinalamos como são estruturados estes cursos, focando especialmente nos dois cursos realizados em 2013/2 e 2014/1 sob a coordenação da profa. Dra. Cláudia Mortari e do prof. Dr. Paulino de Jesus Francisco Cardoso, com recursos oriundos dos Editais PROEXT 2011 e UNIAFRO IV, ambos do governo federal. 
O curso ${ }^{7}$ financiado pelo UNIAFRO IV, denominado Formação de Professores: produção e difusão de conteúdos sobre história e cultura afro-brasileira e africana ${ }^{8}$, de grande abrangência e impacto na educação básica, voltado exclusivamente para formação de professores(as) atuantes no estado de Santa Catarina, foi realizado no formato semipresencial, sendo que a maior parte da formação foi realizada a distância (140 horas), via Plataforma Moodle, e as formações presenciais (40 horas) realizadas aos sábados (em cada polo), totalizando uma carga horária de 180 horas. Os polos abarcavam cinco cidades-sede, uma em cada região do estado (Criciúma, Florianópolis, Chapecó, Joinville e Lages), sendo que se inscreveram no curso 680 cursistas. Quanto ao curso sistematizado com recursos do PROEXT 2011, denominado Introdução aos Estudos Africanos e da Diáspora ${ }^{9}$, foi realizado totalmente na modalidade a distância, voltado principalmente para professores(as) das diferentes redes de ensino, atuantes em todo o país, não sendo restrito ao estado de Santa Catarina. Foram disponibilizadas 500 vagas para inscrição, sendo 140 horas a carga horária integral do curso. Na sequência destacamos imageticamente como se organizava uma sala do curso no Moodle e seu layout de navegação.

Os objetivos dos cursos focalizaram a capacitação de professores (as) da rede pública de ensino em alguns temas relativos à História das Áfricas e das populações afrodescendentes, visando contribuir para a implementação dos princípios e fundamentos contidos nas Diretrizes Curriculares Nacionais para a Educação das Relações Étnico-Raciais e para o Ensino de História e Cultura Afro-brasileira e Africana.

${ }^{7}$ Informações mais detalhadas e aprofundadas sobre o curso em questão encontram-se disponíveis em: CARDOSO, Paulino de Jesus Francisco; LIMA, Graziela dos Santos; PACHECO, Ana Júlia; RASCKE, Karla Leandro. Ensino de Áfricas e relações raciais: o curso do UNIAFRO IV realizado pelo NEABUDESC e a formação de professores (Santa Catarina, 2014). NEAB-UDESC, 2015. Texto não publicado.

${ }^{8} \mathrm{O}$ material didático do curso foi elaborado por professores e professoras qualificados(as) na temática que construíram narrativas reflexivas com base em temas norteadores de cada capítulo, embasados em 4 Módulos distintos, a constar: Módulo 1 - Introdução e utilização da Plataforma Moodle (ambientação); Módulo 2 - Relações Étnico-Raciais na Sociedade; Módulo 3 - Introdução a História da África; Módulo 4 - História das Populações de Origem Africana no Brasil. Consultar: CARDOSO; RASCKE, 2014.

${ }^{9}$ Também os conteúdos do curso Introdução aos Estudos Africanos e da Diáspora foram sistematizados por reconhecidos(as) professores(as) na temática, contando com 3 Módulos: I - O ensino de História das Áfricas: alguns apontamentos; II - História das Áfricas (séculos XVI e XIX); e III - Experiências das populações africanas e afrodescendentes na diáspora brasileira. Consultar: MORTARI, 2015. 
Imagem 1 - Sala virtual utilizada na plataforma Moodle da UDESC

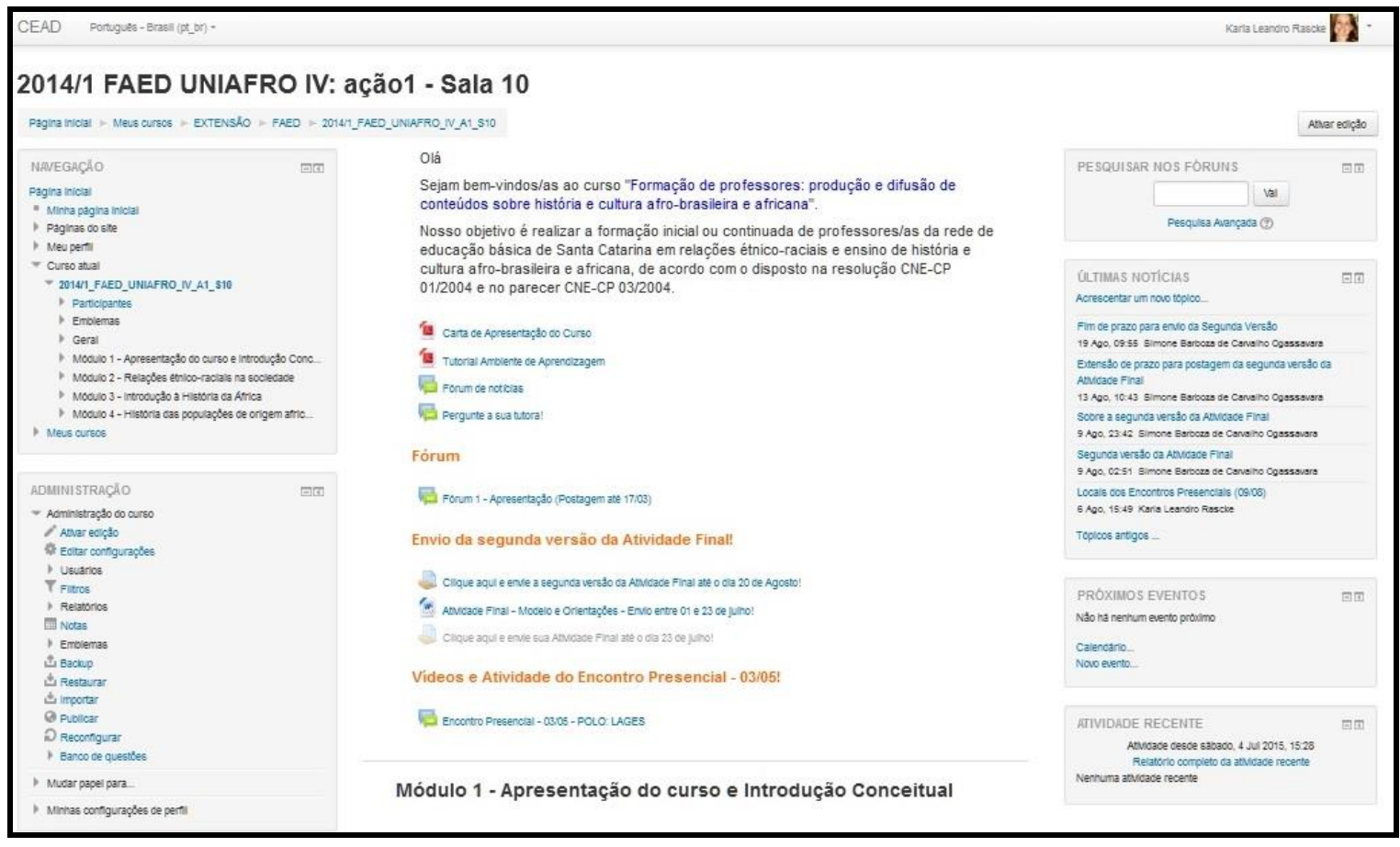

Fonte: Print da página da Plataforma Moodle, sala 10, curso Formação de Professores.

A sistemática de ambos se pautou na contratação de professores (as) especialistas para a organização escrita textual do material (conteúdos) do curso, além das indicações de material complementar (textos, sites, vídeos, etc.) relativo a cada capítulo abordado. A equipe de especialistas foi selecionada com base na formação de cada professo r(a), sendo todos (as) mestres (as) e doutores (as) atuantes em atividades de formação continuada ou inicial e, oportunamente, com abordagens e estudos na temática do curso, constando em sua maioria de profissionais das áreas de educação e história, voltados(as) ao campo da educação das relações étnico-raciais e história africana e afro-brasileira.

Toda a equipe foi devidamente remunerada de acordo com as tabelas e relações de pagamento estipuladas pela Universidade do Estado de Santa Catarina, seguindo o padrão de contratação de especialista utilizado por esta instituição de ensino. Assim, coordenação pedagógica, coordenação de projetos, coordenações de tutoria, professores (as) tutores (as), professores (as) conteudistas e formadores (as), bem como os (as) oficineiros (as) atuaram nesta parceria com pagamento realizado pela universidade a partir dos recursos obtidos no projeto UNIAFRO IV e no PROEXT-Sesu 2011. Não seguimos os valores e modelos apresentados pelo sistema da Universidade Aberta do 
Brasil (UAB), pois os recursos e as atribuições de cada profissional envolviam um caráter próprio do curso, um pouco distinto do que ocorre no sistema $\mathrm{UAB}^{10}$.

A equipe de professores(as) conteudistas elaborou os materiais base para o curso, indicando os complementares também, que foram devidamente compartilhados em cada uma das salas do Moodle reservadas para os cursos, sendo 10 salas com média de 60 cursistas em cada uma para o UNIAFRO IV e 10 salas com 50 cursistas cada para o PROEXT-Sesu 2011. Os professores tutores ${ }^{11}$ e tutoras atuaram como responsáveis pelas salas virtuais, um (a) em cada sala, dirimindo dúvidas, alertando para o calendário e os prazos de cada atividade, fóruns e entrega do trabalho final. Além da mediação no fórum de dúvidas, a cada módulo havia um fórum específico abordando conteúdo, sendo que o (a) professor (a) tutor (a) atuava na mediação das postagens dos cursistas e controle de quem postava e respondia a intervenção do (a) tutor (a) em cada postagem. Os trabalhos finais também foram corrigidos pelo (a) tutor (a) de cada sala.

A equipe de coordenação de projetos, coordenação de tutoria e pedagógica, formada por 4 profissionais da área de História, Educação e Gestão da Informação atuou em parceria com a coordenação geral dos cursos, auxiliando na execução das atividades, formação dos(as) tutores(as), criação de estratégias para manutenção dos cursistas nos cursos (evitando maiores evasões) e acompanhando todas as atividades dos(as) professores(as) tutores(as), conteudistas, formadores(as) e oficineiros (as), além da equipe de bolsistas vinculadas ao NEAB-UDESC responsável por acompanhar os processos de infraestrutura para cada polo e suporte aos demais profissionais da equipe.

Além dos 5 fóruns, os cursos também exigiram a elaboração de uma atividade final, pautada na elaboração de um projeto de ensino-aprendizagem, articulando algumas das temáticas estudadas durante cada curso e formulada a partir do contexto escolar de inserção do (a) cursista. O objetivo da atividade final propunha contribuir para a implementação dos princípios e fundamentos contidos nas Diretrizes

\footnotetext{
${ }^{10} \mathrm{~A}$ nomenclatura das funções manteve-se a mesma em alguns casos, embora a atribuição de atividades e o papel de cada profissional tenha sido explicitada quando da contratação de cada um(a), não seguindo os modelos e os padrões vigentes no sistema UAB, informando ainda que os cursos não contaram com bolsas deste sistema, sendo totalmente financiados pelos editais UNIAFRO IV e PROEXT-Sesu 2011, com contrapartida da Universidade do Estado de Santa Catarina. A UAB possui um sistema, gerenciamento e organização, mas nos cursos que ofertamos, dadas as particularidades, os cuidados com a temática, as abordagens, a estrutura e o financiamento recebido, seguimos metodologia e estratégias próprias.

${ }^{11}$ Em algumas bibliografias o referido cargo aparece apenas com a denominação de tutor, em outras o profissional é nomeado professor on-line. Consultar: ROHDEN, Fabíloa. Gênero, sexualidade e raça/etnia: desafios transversais na formação do professor. Cadernos de Pesquisa, vol. 39, n. 136, p. 157174 , jan/abr, 2009.
} 
Curriculares Nacionais para a Educação das Relações Étnico-raciais e para o Ensino de História e cultura africana e afro-brasileira.

Os trabalhos finais de cada curso foram pensados a partir do enfoque e do público participante, ou seja, professores e professoras das redes de ensino básico, de acordo com sua área de atuação e formação. Neste sentido, como atividade de fechamento, propusemos a organização de um plano de ensino, composto por tema, disciplina (s) envolvida (s), duração da proposta, série/ano, apresentação do projeto, justificativa de realização, objetivos, conteúdos, metodologia, material didático/recursos, avaliação e referências bibliográficas.

Cada projeto foi elaborado por um (a) professor (a) cursista de acordo com sua área de atuação e formação, tendo o acompanhamento do (a) professor (a) tutor (a) de cada sala da Plataforma Moodle. As atividades finais passaram pelo parecer do (a) tutor (a) de cada sala e foram reelaboradas a partir de considerações/sugestões deste (a) docente, no intuito de ampliar discussões, estreitar objetivos, esmiuçar e detalhar a proposta a ser desenvolvida na escola onde o (a) cursista atuava.

Em termos gerais dos cursos, o Formação de Professores contou com 680 inscritos e o Introdução aos Estudos Africanos e da Diáspora com 500, sendo que uma das exigências para permanência nos cursos era realização das postagens nos fóruns dentro do prazo estabelecido no cronograma dos cursos. Neste sentido, como muitos(as) cursistas deixaram de desenvolver as atividades ao longo dos cursos, foram desligados das salas e não receberam certificados. Uma das opções metodológicas e organizacionais das coordenações atuantes nestas duas ações de formação foi a de estabelecer regras de participação nos fóruns, leituras dos materiais do curso e interação com conteúdos da plataforma, além da participação nos encontros presenciais aos sábados, como era o caso do Formação de Professores.

$\mathrm{O}$ intuito, ao estabelecer este critério, pautou-se em formar e certificar os cursistas que tivessem contemplado todas as propostas desenvolvidas nos cursos. Devido a esta forma de lidar com o andamento dos cursos, aliados a outros quesitos como sobrecarga de horas-aula dos professores e professoras em suas escolas, muitos (as) cursistas desistiram ao longo dos cursos. No total, receberam certificação no Formação de Professores 132 cursistas de todo o estado de Santa Catarina. Em relação 
ao curso Introdução aos Estudos Africanos e da Diáspora ${ }^{12}, 168$ foi o total de certificações emitidas.

\section{O(a) professor(a) tutor(a) na construção do conhecimento}

Faz-se necessário, na EaD, elaborar, pesquisar e fomentar trabalhos sobre o papel do (a) professor (a) nesta modalidade de ensino, assim como realizamos nas demais modalidades. O modo de educar e de perceber a educação são elos importantes no momento dessa construção do conhecimento, e na forma como este (a) professor (a) estabelecerá a relação com seus alunos e alunas. Portanto, mais significativo que o próprio espaço é a tomada de decisão do (a) professor (a) frente a seus desafios, e a percepção do significado do ensino.

A construção do conhecimento em nossos cursos, propostos e organizados pelo NEAB-UDESC, ocorreram através de interações, fóruns, e-mails e de um diálogo constante com os (as) participantes (cursistas). Sendo assim, se para nossos (as) alunos (as) que também são educadores (as), a própria modalidade de ensino se apresentava como uma novidade do qual precisavam se habituar e aprender a utilizar as ferramentas disponíveis, os (as) professores (as) tutores (as) compreendiam que o reconhecimento e aprendizagem deste espaço fazia-se importante para a realização do ensino a distância. Porém, reconhecer todas essas ferramentas e saber usá-las com eficiência nem sempre condiz com a significação e elaboração dos conteúdos propostos.

Neste ambiente, tanto aluno (a) quanto professor (a) se tornam protagonistas na utilização e coordenação das ferramentas virtuais de aprendizagem, contudo a intenção do(a) professor(a) extrapola a relação do uso de ferramentas, já que o processo de comunicação, intencionalidade, e cooperação entre os(as) alunos(as) é responsabilidade do(a) professor(a) tutor(a), enquanto outras questões e etapas dessa modalidade envolvem a participação do(a) professor(a) formador(a), designer instrucional e tantos outros. Ser professor (a) tutor (a) significa que atuamos enquanto docentes colaboradores (as) na construção de conhecimento de nossos (as) alunos (as).

${ }^{12}$ Para maiores informações, consultar: ROVARIS, Carolina Coberllini. O Ensino de História da África: apontamentos da experiência em torno do Curso de Formação Continuada de Professores(as). Anais do XV Encontro Estadual de História "1964-2014: Memórias, Testemunhos e Estado", 11 a 14 de agosto de 2014, UFSC, Florianópolis. 
Por ser a EAD uma modalidade de ensino que evidencia a autoaprendizagem, o olhar do (a) professor (a) tutor (a) poderá estar voltado de forma mais direcionada ao ritmo particular de cada aluno (a) (PEROSA; SANTOS, 2006, p. 155). Deste modo, o que frequentemente percebemos, seja no momento das dúvidas ou nas respostas dos fóruns ou mesmo da plataforma, é a necessidade de uma interação ágil, dinâmica e argumentativa com o (a) cursista/aluno (a). A partir do objetivo de construir uma perspectiva sensível às vivências, experiências e histórias dos sujeitos constitutivos dos temas abordados no curso e, consequentemente, debatidos nos fóruns, pensamos em abordagens críticas a ideias preconcebidas e estereótipos. Portanto, lançou-se o desafio de propor formas de pensar, refletir e compreender criticamente as diversidades.

De modo a apresentar como ocorria a interação nos fóruns, segue abaixo parte da postagem de uma professora cursista da sala 6 do curso Formação de Professores, relativa ao Módulo 2 - Fórum 3:

Durante muito tempo a temática das relações étnico-raciais foi silenciada em função do mito da democracia racial. Afinal, se vivemos em uma democracia racial, não há racismo e, portanto, não há necessidade de discutirmos sobre relações étnico-raciais.

Neste sentido, as atitudes e comportamentos são grandes "propagadores de ideias", e no ambiente escolar o exemplo fala muito alto, quando professores calam ou reproduzem o preconceito contido na sociedade.

Assim, também os meios de comunicação, em especial a TV (que é muito assistida pelos alunos), espalham as sementes das ideias racistas, a partir do momento que seus programas têm sempre papeis pré-determinados. [...]

$\mathrm{O}$ texto seguinte aborda a trajetória do movimento negro, identificando suas origens remotas, até as conquistas atuais com a lei e o sistema de cotas.

Neste texto, as associações beneficentes e recreativas (e mesmo as irmandades do período colonial) são identificadas como o cerne do movimento negro no Brasil, ainda que sem uma consciência deste feito e sem utilizar o termo "negro".

[...] Assim, as cotas nas universidades, em empresas, e mesmo as leis 10.639/03 e 11.645/08, são algumas ações afirmativas que buscam reparar os danos causados com anos de discriminação e falta de oportunidades. (Professora cursista, sala 6, UNIAFRO IV, 2014)

A discussão da professora cursista desenvolveu pontos em torno das considerações e reflexões propostas nos textos do módulo 2, dialogando com conceitos em torno da temática da educação das relações étnico-raciais, as imagens e estereótipos construídos e perpetuados na escola, nas mídias e na sociedade. A cursista argumenta e expõe também questões vivenciadas em sua própria trajetória, discutindo teoria, prática 
e transformação social. A intervenção da professora tutora da sala ocorreu na sequência, apontando positivamente o desenvolvimento da argumentação, motivando para novos estudos, conexões, reflexões e comentários e propondo à cursista um aprofundamento em alguns pontos, permitindo novas reflexões e apontando sugestões.

Boa tarde (nome da cursista),

Parabéns pelo texto, está com os argumentos bem postados e demonstra dedicação no momento da leitura e também interesse em procurar os materiais que formam sua base.

No primeiro texto, o documentário sobre a telenovela fala por si só não é mesmo? [...] Você apresentou o papel da escola e como esta pode ou não reproduzir e perpetuar visões e posições diante da vida e do outro, a questão midiática também e creio que seria interessante falar um pouco mais sobre o negro e a África no livro didático e em outros materiais que estão presentes no ambiente escolar.

Já sobre o texto do professor Willian [Robson Soares Lucindo] é importante explorar a FNB e o TEN, pois você já destacou a importância da emergência do MNU, que para de pensar o negro em seus 'vícios da raça'. Como a FNB e o TEN militavam? Quais seus fundamentos e concepções? O que traziam de inovação na luta antirracista?

No texto do professor Paulino [de Jesus Francisco Cardoso] creio ser interessante destacar, para além das leis, as "ações de multiculturalismo": como o autor as define? Citar dois exemplos.

Qualquer dúvida entre em contato! (Professora tutora, Sala 6, UNIAFRO IV, 2014).

Nas respostas dos fóruns, ao pedir novamente que reestruturassem e reavaliassem suas postagens e o modo como todo este processo se dava, estabelecíamos uma relação de confiança com nossos (as) cursistas, assim como podíamos atuar diretamente em questões naturalizadas por eles (as), que denotavam o racismo estruturante em nossa sociedade.

Os (as) cursistas, ao defrontarem-se com o significado de suas escolhas políticas, tendiam a questionar o (a) professor (a) tutor (a), pedindo indicações de mais materiais; passando ele mesmo a colaborar nas trocas de informações com os demais colegas, nos fóruns e na própria pesquisa de novos materiais. Não raras vezes isto ocorreu em nossos cursos, evidenciando o confronto, o conflito entre a prática e as elaborações sobre as desigualdades raciais, o racismo que se aglutina nas relações e a percepção de si frente a estes acontecimentos, isto é a produção de conhecimento que necessitamos quando falamos de ERER.

Por conseguinte, alguns cursistas passaram a correlacionar as teorias, as atividades de avaliação, com a prática escolar, com anúncios, entrevistas e a questionar essas relações. Portanto, quando nossos alunos/cursistas também passaram a incomodar- 
se com tais posturas, acreditamos que uma oportunidade fora posta. Pois o véu que estes sujeitos utilizavam como proteção do não comprometimento com as práticas desiguais do racismo passou a ser questionado e enfrentado. Um exemplo desta percepção envolve a resposta de um professor cursista da sala 2, UNIAFRO IV, a respeito de termos, conceitos e as ações afirmativas:

\begin{abstract}
No primeiro texto eu gostei muito de ter uma noção histórica da ideia social raça, também de ler sobre aspectos históricos dos termos negro e afrodescendente $[\ldots]$

$\mathrm{O}$ texto me elucidou realmente como a modernidade europeia forjou a ideia de raça, tal modernidade europeia realmente trouxe alguns avanços culturais e científicos, no entanto foi pródiga em criar preconceitos e é o caso da questão racial e de uma suposta superioridade racial de um grupo de pessoas que não se comprova. [...]

Sobre as ações afirmativas eu entrei no primeiro vestibular da UFSC em que houveram cotas, na época meu meio realmente era enviesado pois eu vinha de escola particular do interior do estado onde não tive convivência negros, na época eu não era contrário as ações afirmativas, só que não entrei na discussão. Meus anos de universidade me comprovaram que as cotas realmente são uma medida acertada, de forma que a desigualdade de oportunidades no Brasil é visível. Se quisermos um país democrático creio que no caso da universidade pública é necessário equilibrar oportunidades de acesso. [...] (Professor cursista, Sala 2, UNIAFRO IV, 2014/1)
\end{abstract}

Enquanto professores (as) não somos ingênuos (as) em acreditar que tocaremos a todos (as), posto que o racismo é uma prática de poder e manutenção de privilégios. Todavia, após discussões e abordagens críticas ao eurocentrismo e ao racismo, educadores (as) cursistas passaram a ter condutos para elaboração do que antes quiçá intuíam, ou ainda preferiam proteger-se dentro do espaço democrático do racismo universal na manutenção do "somos todos iguais". Suas práticas não poderão irredutivelmente ser naturalizadas, suas verdades, seu sistema de pensamento no qual se forjaram tornaram-se conflituosos.

A atuação da tutoria, a formação continuada em ERER e a capacidade de elaboração dos (as) cursistas provocaram em si mesmos um problema ético, na escolha de qual caminho seguir, decisão esta que depende das suas ressignificações, e de posicionamentos políticos na sua relação com os outros e do que estes (as) almejam dentro da coletividade em que nos encontramos como cidadãos (ãs), educadores (as) e sujeitos produtores de conhecimento. Desejamos, enquanto equipe docente preocupada com a formação dos (as) cursistas, despertar em cada um (a) multiplicadores. Atacar o silêncio da violência, a crença da impunidade, seja ela dentro do espaço escolar ou nas vivências cotidianas, transformando o (a) aluno (a) e o (a) professor (a) tutor (a) em 
sujeitos de produção de autonomia, pois a cada resposta se contesta a uma hegemonia cultural.

\section{A formação do (a) professor (a) tutor (a)}

Manara e Freitas (2011) chamam atenção para as múltiplas atribuições/funções que podem ser exercidas pelo (a) professor (a) tutor (a) de acordo com as demandas e orientações existentes em cada instituição de ensino ou local de atuação deste (a) docente. Segundo as autoras, constituem tarefas realizadas por este profissional a atuação como “orientador, apresentando e desenvolvendo hábitos e estratégias de estudo, na investigação e pesquisa, auxiliando no encontro de soluções para problemas de aprendizagem e realizando mediações pedagógicas" (MANARA; FREITAS, 2011, p. $4)$.

Destacamos que em cada curso a distância o papel do (a) professor (a) tutor (a) é projetado de forma particular (TORRES, 2007, p. 32), sendo que sua atuação enquanto docente terá diferenças a partir destes limites estabelecidos dentro da equipe docente que opera no curso. Este (a) educador (a), muitas vezes, mesmo sem conhecer pessoalmente seus (suas) cursistas, procede no sentido de promover vínculos, laços de aproximação e um ambiente acolhedor, propício à aprendizagem (FARIA, 2010, p. 34).

No caso dos cursos que abordamos neste texto, o (a) professor (a) tutor (a) constituiu-se em agente mobilizador do conhecimento, dialogando com cursistas constantemente, em termos de discussão de conteúdos, debate de ideias, acompanhamento dos prazos do curso, postagens nos fóruns de dúvidas e participação direta em todos os processos de correção de atividades e fóruns questionadores.

A formação deste profissional variou de acordo com o perfil e os objetivos dos cursos. Em nosso caso, quatro professoras tutoras, que atuamos nos dois cursos de formação de professores (as) mencionados anteriormente, possuímos formação na grande área de Ciências Humanas, voltando olhares e pesquisas para relações étnicoraciais e estudos das diásporas africanas, destacando a afinidade com a temática.

Além da formação específica construída ao longo de nossas trajetórias de ensino, lutas sociais e estudos, a realização de formações presenciais sobre as temáticas, distribuídas em módulos de cada curso, foram realizadas pelo prof. Dr. Paulino Cardoso e pela profa. Dra. Cláudia Mortari, refinando as propostas dos cursos e esmiuçando possíveis dúvidas em termos de conteúdos para abordagem e atuação necessária do (a) 
professor(a) tutor(a) em cada uma das salas virtuais, sendo cada docente responsável por uma sala com aproximadamente 50 a 60 cursistas.

A formação adequada deste profissional contribui significativamente para o bom andamento do curso e possibilita aos cursistas maior segurança, confiança e diálogo dentro do ambiente virtual. Como bem pontua Torres, "o delineamento mais preciso do papel de tutor pode favorecer as instituições que promovem a EaD, na medida em que define as atribuições e os parâmetros do cargo" (2007, p. 30).

A capacitação do (a) professor (a), em todos os níveis de ensino, é fundamental para a implementação da Lei Federal 10.639/03, pois a sala de aula, muitas vezes, é o único espaço em que crianças e adolescentes possuem condições e estímulos de acessar conteúdos, informações e saberes sobre as populações africanas e seus descendentes na diáspora. Neste sentido, a formação do (a) professor (a) tutor (a) dentro da temática na qual atua é fundamental, pois torna-se responsável pela formação de professores (as) profissionais em sala de aula, nas mais diversas disciplinas, visto que a temática é transversal. E, para problematizar, refletir e discutir temas em torno das Áfricas, das populações de origem africana no Brasil e da educação das relações étnico-raciais, tão caros à sociedade brasileira, ainda envolvida com os ideais do mito da democracia racial, constitui fundamental o papel do (a) professor (a) tutor (a) no enfrentamento de “concepções hegemônicas e enfrentarmos as desigualdades e os preconceitos incrustados na sociedade brasileira" (ROVARIS, 2014, p. 05).

\section{Considerações finais}

Este texto procurou desenvolver reflexões a partir de experiências de tutoria a distância realizadas pelo NEAB-UDESC em cursos de formação para professores (as), em especial no que tange aos assuntos relativos a História da África e da diáspora e ERER. Evidenciamos, ao longo desta produção, apontamentos a respeito dos espaços institucionais consolidados para a implementação da Lei Federal 10.639/03 e como podemos atuar no sentido de efetivar sua concretização, permitindo que estas abordagens, conteúdos e reflexões alcancem cada vez mais profissionais da educação.

Oportunamente, tendo em vista o foco objetivado neste trabalho, mobilizamos discussões em torno do efetivo papel do (a) professor (a) tutor (a) que atuou nestes cursos de forma significativa e fundamental na construção do conhecimento dos (as) 
cursistas das mais distintas áreas. Percebemos que a prática dos (as) professores (as) tutores (as) não é idêntica à prática dos (as) professores (as) na sala de aula presencial, pois entendemos serem espaços distintos de aprendizagem, caracterizados por metodologias e ferramentas diferentes, adequadas aos seus contextos e realidades, permeados de peculiaridades (TORRES, 2007, p. 33).

\section{REFERÊNCIAS}

BORGES, Fabiana Vigo Azevedo; REALI, Aline Maria de Medeiros. Formação de Professores e Educação a distância: uma parceria na formação de professores-tutoresregentes. Anais do SIED- Simpósio Internacional de Educação a Distância; EnPED Encontro de Pesquisadores em Educação a Distância. Universidade Federal de São Carlos (USCar).

CARDOSO, Paulino de Jesus Francisco; RIBEIRO, Neli Góes; RASCKE, Karla Leandro; LIMA, Graziela dos Santos; PACHECO, Ana Júlia; JESUS, Maria Gerlane Santos. Formação para a educação das relações étnico-raciais: experiências em cursos de formação continuada NEAB/UDESC. Revista em Extensão (Online), v. 13, p. 9-19, 2014.

CARDOSO, Paulino de Jesus Francisco; RASCKE, Karla Leandro (Orgs.). Formação de professores: produção e difusão de conteúdos sobre história e cultura afro-brasileira e africana. $1^{\text {a }}$. ed. Florianópolis: DIOESC, 2014.

FARIA, Elísio Vieira de. O tutor na Educação a Distância: A construção de conhecimentos pela interação nos ambientes midiáticos no contexto da educação libertadora. Scientia FAER, Olímpia - SP, Ano 2, Volume 2, $1^{\circ}$ Semestre. 2010, p. 28 37. Disponível em: <http://www.faer.edu.br/revistafaer/artigos/edicao2/elisio.pdf >. Acesso em 4 abr. 2015.

GOMES, Gustavo Manoel da Silva. Historiografia e Ensino de História para a descolonização do conceito de cultura afro-brasileira: articulando ciência, ensino, cultura e política. Revista Lugares de Educação, Bananeiras-PB, v. 5, n.10, 2015, p. 93-111.

IVASHITA, Simone Burioli; COELHO, Marcos Pereira. EaD: o importante papel do professor-tutor. Anais do IX Congresso Nacional de Educação, III Encontro Sul Brasileiro de Psicopedagogia. PUC-PR, Paraná, 2009, p. 7550-7560. Disponível em: <http://www.pucpr.br/eventos/educere/educere2009/anais/pdf/2865_1873.pdf >. Acesso em 4 abr. 2015.

MANARA, Alécia Saldanha; FREITAS, Indianara. O Trabalho Docente do Professor Tutor na Educação à Distância. In: Anais da $3^{\text {a }}$ Jornada Acadêmica Mestrado em Educação-Unisc. Santa Cruz do Sul: Unisc, 2011. v. 1. p. 01-18. Disponível em 
<http://www.unisc.br/portal/upload/com_arquivo/o_trabalho_docente_do_professor_tut or_na_educaacaao_aa_distaancia.pdf>. Acesso em 4 abr. 2015.

MOREIRA, Geraldo Eustáquio; ALMEIDA, Luiz Eduardo Siqueira de. Como enfrentar o racismo em escolas públicas: conquistas e desafios. Revista EDaPECI, São Cristóvão (SE), v. 14, n. 2, 2014, p. 403-419. Disponível em: <http://www.seer.ufs.br/index.php/edapeci/article/view/1872/pdf>. Acesso em 4 abr. 2015.

MORTARI, Claudia (Org). Introdução dos Estudos Africanos e da Diáspora. Florianópolis: DIOESC, 2015.

MUlLER, Tânia M. P. \& COELHO, Wilma de N. B. A Lei 10639 e a Formação de professores: Trajetória e Perspectivas. Revista da ABPN, v. 5, n. 1, jul.- out. 2013 • p. $29-54$.

PEROSA, Gilse T. Lazzarini; SANTOS, Marcelo dos. Interatividade e aprendizagem colaborativa em um grupo de estudo online. In: SILVA, Marco (Org.). Educação online: teorias, práticas, legislação, formação corporativa. São Paulo: Edições Loyola, 2006.

ROHDEN, Fabíola. Gênero, sexualidade e raça/etnia: desafios transversais na formação do professor. Cadernos de Pesquisa, vol. 39, n. 136, p. 157-174, jan/abr, 2009.

ROVARIS, Carolina Coberllini. O Ensino de História da África: apontamentos da experiência em torno do Curso de Formação Continuada de Professores(as). Anais do XV Encontro Estadual de História "1964-2014: Memórias, Testemunhos e Estado", 11 a 14 de agosto de 2014, UFSC, Florianópolis.

SECADI, Secretaria de Educação Continuada, Alfabetização, Diversidade e Inclusão. Plano nacional de Implementação das diretrizes curriculares nacionais para a educação das Relações Étnico-Raciais e para o ensino de História e Cultura Afrobrasileira e Africana. MEC, Brasília, 2009.

TORRES, Camila Costa. A educação e a distância e o papel do tutor: contribuições da ergonomia. Tese de Doutorado (Programa de Psicologia) - Universidade de Brasília (UnB). Brasília, 2007.

\section{Como referenciar este artigo}

CARDOSO, Paulino de Jesus Francisco et al. Formação continuada em educação das relações étnico-raciais: o(a) professor(a) tutor(a) na construção do conhecimento. Revista Ibero-Americana de Estudos em Educação, Araraquara/SP, v. 11, n. 3, p.1389-1408, 2016. Disponível em: 〈https://dx.doi.org/10.21723/riaee.v11.n3.8018>. EISSN: $1982-5587$.

Submetido em: 16/09/2015

Aprovação final em: 12/07/2016 